\title{
Analysis of REDD+ policy networks in Peru
}

\author{
Mary Menton, Javier Perla, Juan Sotes and Leandra Fatorelli
}

\section{Key messages}

- The REDD+ policy arena in Peru involves a wide range of actors, governmental as well as civil society, although the environmental and forest sectors predominate. Peruvian government actors show high levels of reputational power while non-governmental actors, international as well as national, dominate the information exchange network. Within the information network, the national REDD+ Group (Grupo REDD+ Perú), a multi-stakeholder forum created for dialogue concerning REDD+, stands out as an important intermediary between different actor groups.

- Although different groups of actors highlighted different challenges for REDD+ implementation, the interviewed actors declared very few disagreements with other actors. The exception is the position of the Interethnic Association for the Development of the Peruvian Rainforest (AIDESEP) that has been at the center of the few protests concerning REDD+ at a national level. AIDESEP expresses the need to create an indigenous REDD+ mechanism focused on defending the territorial rights of indigenous peoples and supporting communal forest management, instead of searching for solutions by means of the carbon market.

- A group of principal actors stands out as having more interaction in the study networks, showing high rates of communication and collaboration with other principal actors. They include representatives of the Government, diverse NGOs, private sector and donors. However, the governmental actors that most influence development policies, and thus the drivers of deforestation, are not part of the group of principal actors identified through the network analysis. This lack of intersectorial integration represents one of the biggest challenges for REDD+ implementation.

\section{REDD+ in Peru}

Like many of the REDD+ (Reducing Emissions from Deforestation and Forest Degradation Plus) pilot countries, Peru is involved in several international initiatives (FCPF', UNREDD², etc.) that support the preparation phase, or "REDD+ readiness". By 2012, Peru had received investment commitments totaling 29 million USD for REDD+ initiatives, of which more than half was destined for civil society (Forest Trends 2014). Part of these funds supported the creation of the Project REDD+ of the Ministry of Environment $(\mathrm{MINAM})^{3}$. The project is focused on supporting the development of the national REDD+ strategy, capacity building and the creation of a MRV (measurement, reporting and verification) system. Peru will also be a recipient of the Forest Investment Programme Fund (FIP) that has committed to investing up to 50 million USD ( $54 \%$ donation, $46 \%$ loan) in the reduction of deforestation, of which 14.5 million USD will go to the titling of indigenous territories and their governance.

\footnotetext{
The Forest Carbon Partnership Facility

2 Support program for processes of national development of REDD of the United Nations.

3 The project "Supporting the implementation of REDD+ in Peru" financed by KfW (German Development Bank), and the project "Technical, Scientific and Institutional Capability Building for the Implementation of REDD+ in Peru"financed by the Gordon and Betty Moore Foundation, have been united in one project, called REDD+ MINAM, which consolidates a project with more far-reaching results (MINAM, 2014).
}

MINAM has taken a leading role in the development of the national REDD+ strategy, initiating an intersectorial participation process that includes other actors of the Government (Ministry of Agriculture, regional governments, among others) and civil society (Che Piu and Menton 2014). Coordination efforts have recently increased due to initiatives under MINAM's Project REDD+, yet they have not reached general consensus concerning the viability or the desirability of the mechanism, nor the best options for its implementation. Many perceive these initiatives as an opportunity for the country to improve local economies, promote private investment and preserve ecosystem services. In terms of reduction of emissions, some actors do not agree with the way in which REDD+ is being designed and implemented. One of the most representative cases is that of AIDESEP (the Interethnic Association for the Development of the Peruvian Amazon) that seeks a different approach to REDD+: to strengthen the rights of indigenous peoples in the face of potential encroachment on their rights by REDD+ projects (Espinoza and Feather 2011). Since the country has opted for the nested approach, there is another important disagreement that can be seen in the debates concerning the development of MRV. In particular, how the subnational initiatives and the regional reference scenarios can be reconciled with nationallevel MRV. 
Analysis of REDD+ policy networks Given this scenario of multiple actors with different interests
and priorities, we sought to understand the interactions within national REDD+ actor networks, through a policy network analysis (PNA) using social network methodologies (Perla et al. 2014). The study contributes to Module 1 of CIFOR's Global Comparative Study on REDD+ that includes a series of REDD+ PNA studies in the case-study countries (Brockhaus and DiGregorio 2012; Brockhaus et al. 2014). Social networks are composed of a finite group of actors and the relationships between them: the pattern of relationships defines the structure of the network (Wasserman and Faust 1994). Social networks are graphically represented by nodes (representing the actors) and lines (representing their relationships) (Scott 2000). These relationships can be understood on the basis of their directionality (directed or undirected) or their density (quantification of the ties between nodes/actors). The actors have a limited number of ties since their time and energy resources are limited. The analysis of policy networks provides an understanding of the interactions between the actors that influence the formation of public policies. It illustrates the role of civil society and the private sector in the arena, outlines key actors that act as intermediaries between different groups of actors, and is able to identify barriers and opportunities concerning the flow of information and collaboration within the network.

Through a stakeholder analysis and a consultation with a group of national REDD+ experts in August 2012, 85 national level actors were selected as the most relevant in the REDD+ policy arena. A two-part interview was requested with each actor: (1) a semi-structured interview regarding the participation of the institution in REDD+ and its opinions on the challenges and opportunities that REDD+ offers and (2) a structured survey that consisted of questions about the institutional position concerning REDD+ and a matrix of the institution's interactions with other members of the network. The interactions were evaluated in terms of the following questions and networks:

- Which institutions are particularly influential in national REDD+ policy formation? [prestige network]

- Which institutions do you discuss and exchange information with, regularly or periodically, concerning questions related to national REDD+ policies? [information exchange network]

- Which institutions do you depend on to obtain relevant scientific information on REDD+? [scientific information network]

- Which institutions do you disagree with on issues related to REDD+ policies? [disagreement network]

- Which actors do you collaborate with periodically on issues and policies related to REDD+? [collaboration network]

We were able to interview 52 of the 85 actors, with better response rates among the actors with offices in the capital (Lima). Despite the fact that regional actors ${ }^{4}$ play an important role in the development of REDD+ and deserve an additional analysis, carrying out visits to the regions was beyond the scope of the study. As a result, only eight regional actors participated in the surveys due to problems of transportation and communication.

4 For example, regional governments, regional REDD+ groups, indigenous REDD+ roundtables and other actors with headquarters outside of Lima.
Table 1. Category of actors and color in the network

\begin{tabular}{l|l}
\hline Category of actors & \multicolumn{1}{c}{$\begin{array}{l}\text { Color in the } \\
\text { network }\end{array}$} \\
\hline Government & \\
\cline { 2 - 2 } National research institutes & \\
\cline { 2 - 2 } National companies & \\
Professional associations & \\
National environmental NGOs & \\
National indigenous NGOs & \\
International environmental NGOs \\
International indigenous NGOs \\
International intergovernmental \\
organisms \\
International companies \\
International organizations \\
Multi-stakeholder REDD+ Groups
\end{tabular}

The interviewed actors were divided into categories, as shown in Table 1. Each category is represented by a color that will be used in the figures throughout this brief.

\section{Challenges for REDD+}

Via semistructured interviews, we evaluated perceptions concerning the biggest challenges for REDD+ in Peru. Notably, the interviewees did not indicate any of the drivers of deforestation or degradation ${ }^{5}$ as principal challenges for REDD+ in the country, but focused on governance, technical and conceptual aspects. The challenge identified by the highest percentage of actors (37\%) was the complexity of the mechanism and the international framework in which it is being developed. Half of the government actors mentioned this as a challenge. The topic of complexity is highly relevant because, even though the underlying idea of REDD+ is simple, quite complex questions relating to measurement, scale, financing, permanence, responsibility, leakage and reference levels remain unresolved.

The second challenge, weak governance, was cited by a large number of actor categories, yet by few government actors (20\%). The actors most concerned with weak governance were donors and environmental NGOs (national and international). No particular definition of governance was identified, but the incipient character of certain institutions (MINAM was formed

5 Within a context of economic growth and migrations from the mountain areas to the rainforest, the direct motors of deforestation and degradation in Peru include agriculture, extractive activities (mining, hydrocarbons, timber harvesting) and the expansion of infrastructure (roads, hydroelectricity) (Che Piu and Menton 2014). 
in 2008) was mentioned, as well as corruption and the lack of capacity and institutional memory.

The third and fourth challenges, linked to governance, were insufficient coordination between the different governmental institutions and the limited flow of information between actors. REDD+ is advancing in Peru via several distinct initiatives, by actors from the public and private sectors and NGOs, without one organization or system that centralizes the generated information. MINAM's Project REDD+ is in the process of consolidating the initiatives and assuming this role. The actors mentioned the role of the national-level REDD+ Group, which makes a great effort to gather and distribute information, as a space where findings and initiatives can be shared.

In contrast to the rest of the challenges identified by interviewees, which focus on technical aspects or the wider context in which REDD+ develops, the discourse of the indigenous representatives criticizes much more explicitly the model that is being followed. While the government presents REDD+ as a forest conservation mechanism, AIDESEP maintains that it is oriented towards the carbon market. AIDESEP offers a distinct approach and describes its indigenous REDD+ proposal as "REDD+ beyond carbon and the market". Distrust by indigenous communities has been identified as a challenge by other organizations. Most of the protests related to REDD+ in Peru have been led exclusively by indigenous representatives. At the same time, the government decided to include the requests of AIDESEP to increase the focus on indigenous peoples' tenure rights in the development of the FIP. As a result, there has been closer alignment between indigenous actors and the national government during the last few months.
The structured surveys show that there is wide consensus between the opinions of the actors in questions concerning: "What should REDD+ be like?" and "What challenges will you find on the way?" However, there is not as much agreement on the expectations regarding how it will work when the relevant policies have been developed. The issues that create most disagreements refer to economic and technical questions, such as who should carry out the accounting and payments, who should be included as beneficiaries, and the need for nationallevel management. Contested issues include the outcomes for the potential co-benefits of REDD+ such as poverty relief or the conservation of biodiversity.

\section{Information exchange and collaboration networks}

Below we present findings from analysis of the interaction networks. For all figures, the colors represent the actor categories.

Analyzing the information exchange network, with the actors grouped into categories, we can observe how the national environmental NGOs constitute the most important group and the one that is the best informed about REDD+ (Figure 1). They manage a high percentage of projects focused on REDD+ and show higher rates of communication. Even so, these same actors say that improving the flow of information is an important challenge facing REDD+. They consider that there are certain types of information for which access is difficult, and certain actors that are outside the communication networks or create barriers to access and transparency.

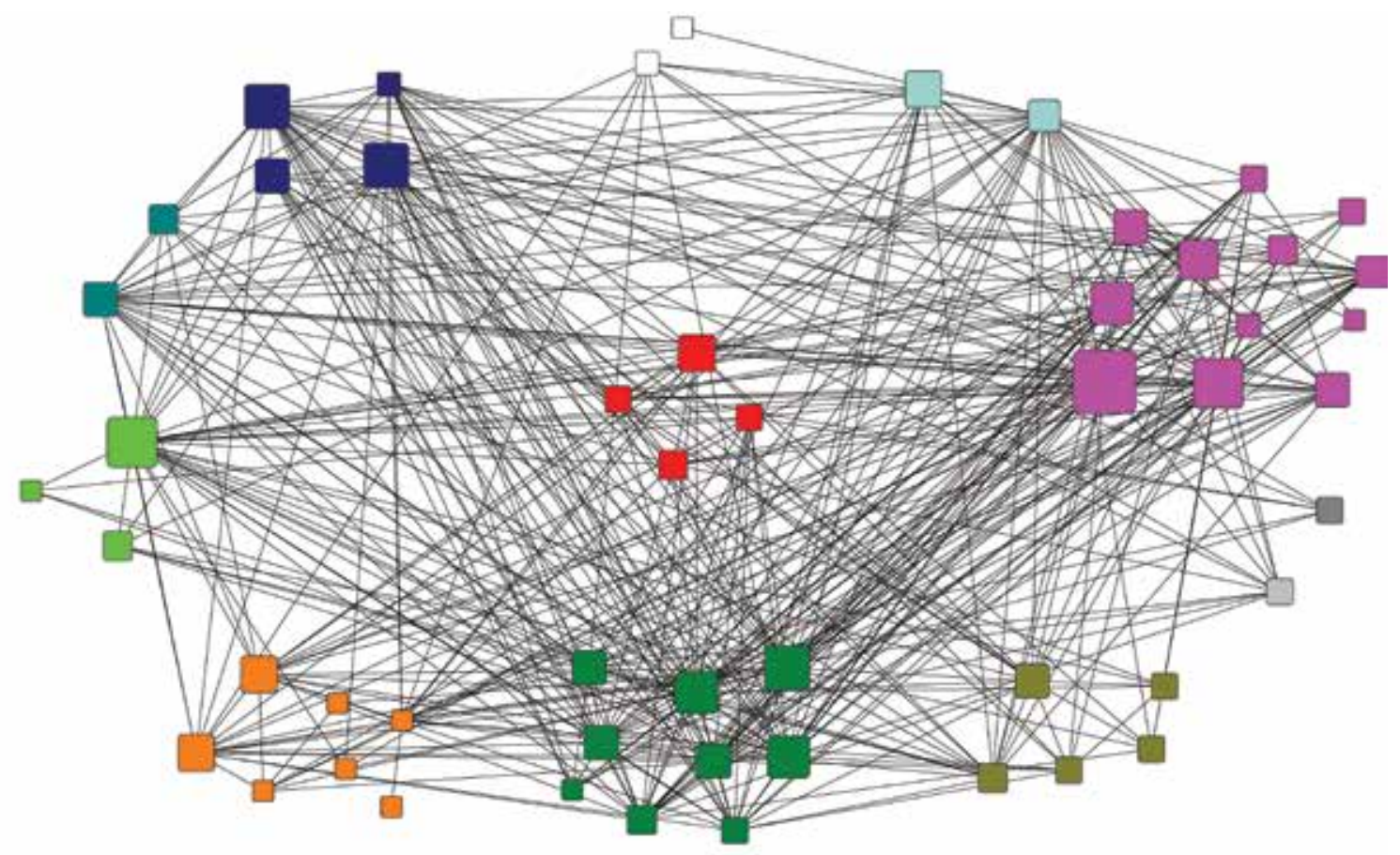

Figure 1. Information exchange network. The size of the nodes indicates the number of other actors that confirm exchanging information with that actor. 


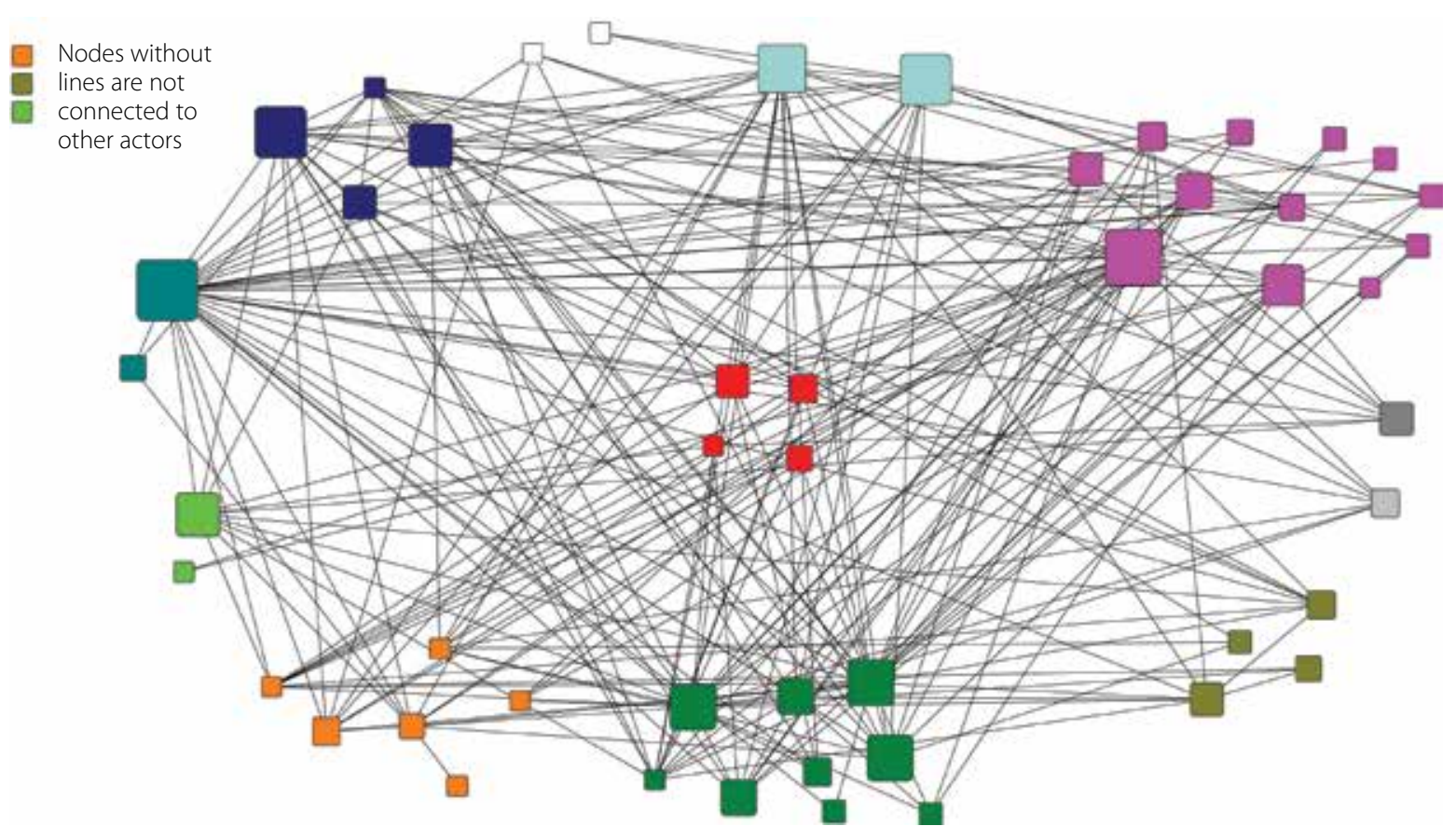

\section{Figure 2. Scientific information network. The size of the nodes is larger in the case of actors that are greater sources of scientific information.}

Twenty-one percent of all possible ties between actors (i.e. each actor would communicate with all other actors in the network) are realized. This represents a low value, but is conditioned by the fact that this is a large network, with a large number of potential interactions. Actors have limited time and resources to maintain these connections. The national REDD+ Group, the environmental NGOs and international and national research institutes stand out as actors that provide the principal sources of information.

In the scientific information network (Figure 2), MINAM-Climate Change (responsible for coordinating governmental REDD+ activities during the interview period) and intergovernmental organizations have a leading role. The production of scientific information and access to it (like all information control) constitutes a form of power that could legitimize the importance of the scientific discourse in policy formation. Nevertheless, the majority of interviewees agreed with the statment "scientists should be the highest authority on REDD+" but also assessed that they currently do not dominate the national debate.

\section{Disagreements}

AIDESEP led four of the five protests ${ }^{6}$ identified by the panel of experts. The dominance of AIDESEP in protests and the lack of participation of other actors illustrate a relatively low conflict scenario in the national sphere. The lack of participation in protests and the lack of declarations of disagreements could be due to a consensus concerning REDD+. Equally, it could be an indication of the incipient nature of the REDD+ process in the country and the lack of participation of many local actors who have not

6 An event of collective action such as demonstrations, strikes or letters, which express criticism and/or political demands. organized around the issue or have not yet been exposed to the concept of REDD+. The limited articulation of disagreement can be a consequence of there not being enough time for protests or disagreements between the actors to emerge. However the politics of the decision to declare, or not, disagreements with other actors of the network should also be taken into account.

As can be seen in Figure 3, most of the disagreements between actors are directed towards AIDESEP. Given AIDESEPs participation in protest events, it would make sense for many actors to be in disagreement with them. At the same time, it is important to highlight that the majority of the government actors participate in the disagreement network and that many disagreements that do not appear in the network were mentioned during the semistructured interviews. Several differences of opinion were observed between the actors in the semistructured interviews yet were not manifest in the disagreement networks. This probably means that many actors were reluctant to identify disagreements within the network.

In summary, the main disagreement around the implementation of REDD+ in Peru lies between the representatives of indigenous communities and the rest of the actors. Some of the actors identified these different visions as one of the principal obstacles to the success of REDD+ implementation; for this reason, it is especially relevant to assure AIDESEPs participation in the development of REDD+ policies. The disagreements between Government actors, not shown in the disagreement network but revealed during the semistructured interviews, will have an important influence on the development of national strategy, and highlight the importance of improving the coordination and collaboration between these actors. 


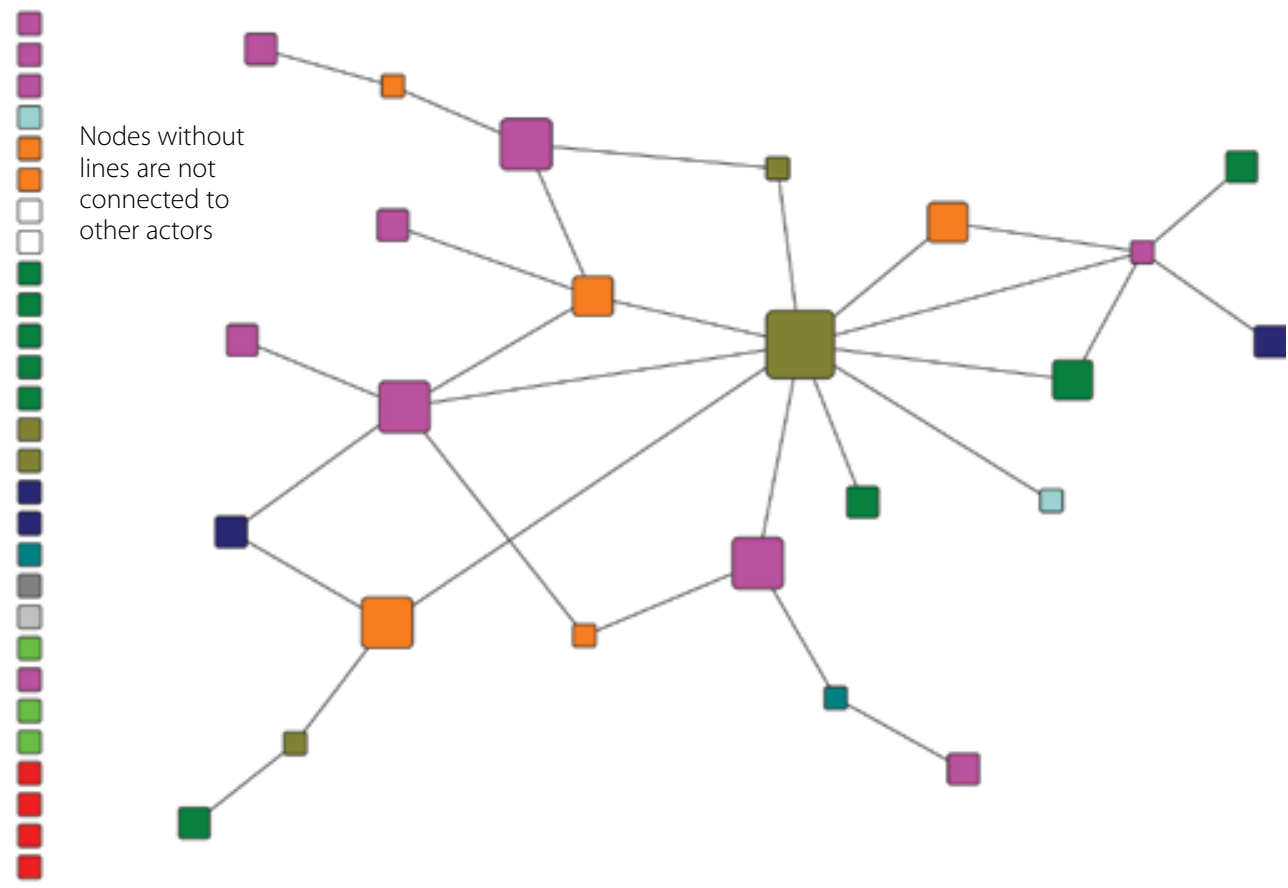

Figure 3. Disagreement networks. The larger the node, the more actors disagree with the actor.

\section{Which actors are the most influential?}

The actors perceive that government actors have the most influence on the development of REDD+ policies. Interspersed amongst the government institutions, some NGOs also stand out. Figure 4 shows the prestige network grouped by actor category.

\section{Principal actors}

In order to identify the principal actors related to REDD+ in Peru and analyze the relationships between them, properties of the prestige, information and collaboration networks were studied: including in-degree for the prestige network, and in-degree, out-degree and betweenness for the information exchange and collaboration networks.

From the broader list of actors, those with the most centrality (i.e. protagonism) in the networks were selected, resulting in a group of 21 principal actors. They are principally environmental NGOs (seven national and three international) and five government actors. It is worth stressing that apart from the Inter-American Development Bank that coordinates the FCPF and FIP initiatives, none of the principal actors represents the interests of economic growth, the extractive (mining and hydrocarbons) or agricultural sectors. The study was carried out before the discussions on FIP gained prominence. It is possible that the Ministry of Economy and Finance (MEF), which has an important role in the FIP, would be more central to the networks in future studies.

Table 2 shows the comparison of the density of the whole network with that of the principal actors in the case of two analyzed networks: information exchange and collaboration. The networks of the principal actors, in information exchange as well as in collaboration, show higher density than the broader networks. This means that the number of interactions compared to the total of possible interactions is greater among key actors.
Table 2. Density in information and collaboration networks

\begin{tabular}{lcc}
\hline Network & $\begin{array}{c}\text { Density of the } \\
\text { entire network }\end{array}$ & $\begin{array}{c}\text { Density of the } \\
\text { network of the } \\
\text { principal actors }\end{array}$ \\
\hline Information & 0.21 & 0.53 \\
Collaboration & 0.09 & 0.32 \\
\hline
\end{tabular}

This might be a significant result; however, it should be taken into consideration that since the principal actors' networks are smaller than the network that includes all the actors, they do not include peripheral actors. The interactions between the 21 principal actors equal $40 \%$ of the total of relationships in the information exchange network and $57 \%$ of the total of relationships in the collaboration network. These values reflect the leading role that these principal actors and their interactions have in the development of REDD+ in Peru.

According to these results, information exchange and collaboration concerning REDD+ in Peru are concentrated among a limited number of actors who interact in a more cohesive network. MINAM is the most important actor when it comes to the flow of shared information; it does not, however, stand out as an intermediary between actors. This variable, betweenness, is shown in the graphic using a circle inside the nodes (Figure 5). The only government actor with high power of intermediation is a regional government, but the most important intermediaries are the national environmental NGOs and the REDD+ Group. All, especially the REDD+ Group, show high values in the number of interactions in the information exchange network. 


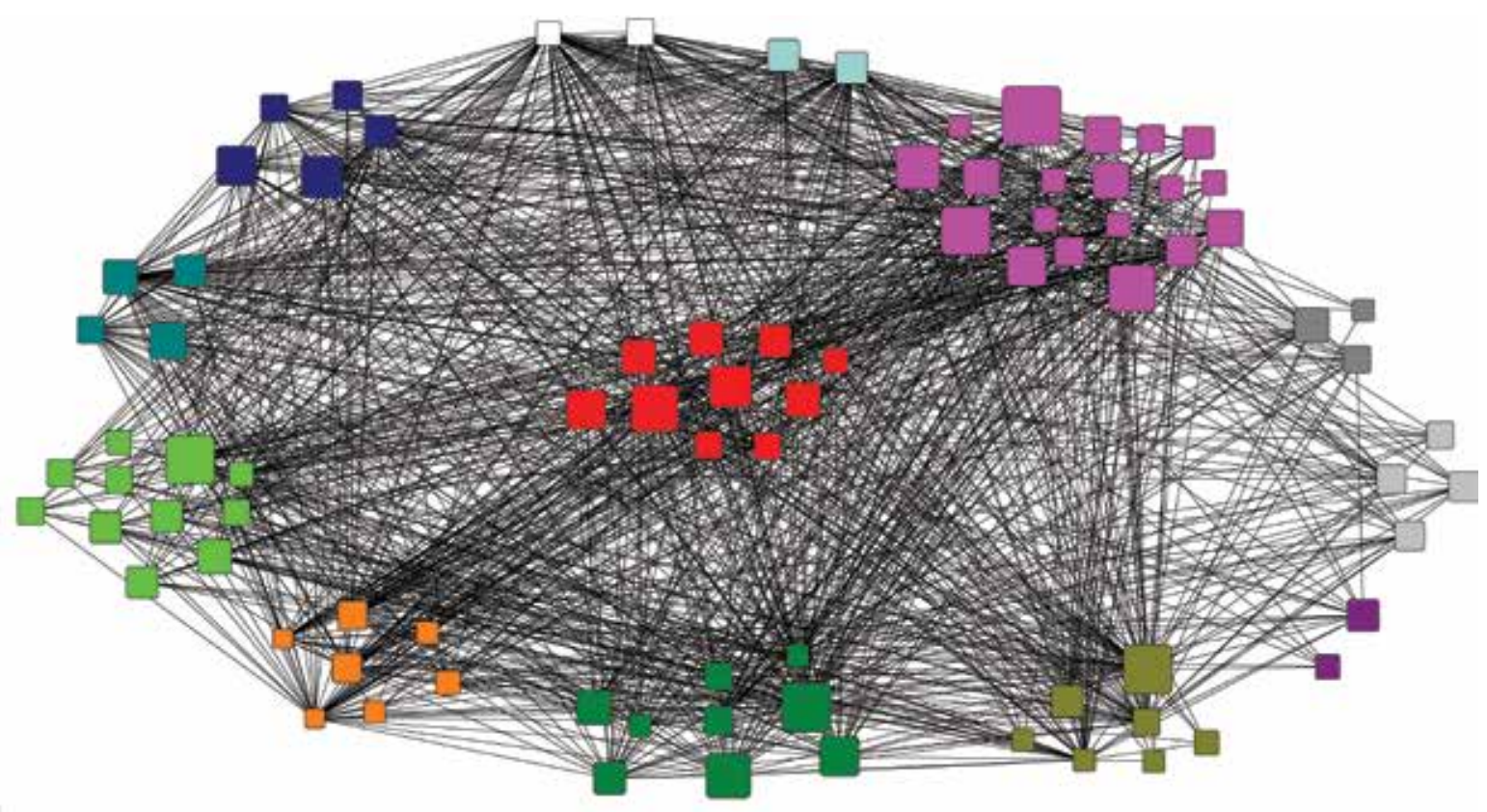

Figure 4. Prestige network. The larger the node, the greater the reputational power of the actor.

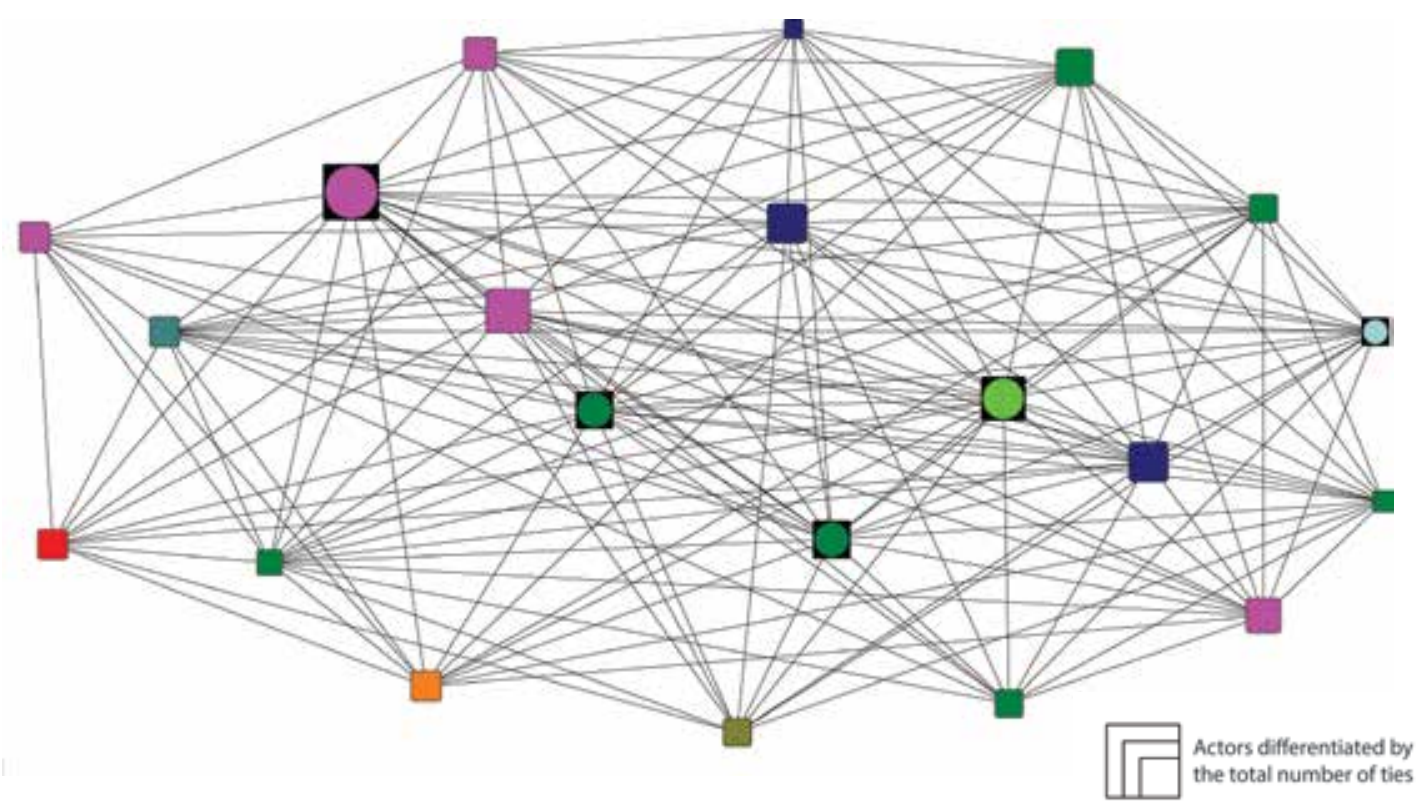

Figure 5. Information exchange network, key actors. 


\section{Conclusions}

The evolution of the REDD+ mechanism in Peru (as in the framework of international negotiations) remains under construction: while there is optimism, many actors lack a clear position in relation to the expectations concerning the impacts of its implementation in the field. This lack of positionality is also seen in the disagreement network (i.e. in the absence of reported disagreements) and in AIDESEP's domination of the protest events without significant participation of other actors in the network.

A significant percentage of the identified actors did not participate in the study, particularly those actors without an office in Lima. It can be inferred that due to problems of transportation and communication, these actors have difficulties in participating in national discussion platforms concerning the development of the mechanism. On the other hand, the limited participation of certain actors, whose actions will be central to the success in the reduction of deforestation, might be symptomatic of a lack of interest in the mechanism's development.

Civil society actors play substantial roles in the networks, particularly national and international environmental NGOs and the national-level REDD+ Group. This group has an important role acting as an intermediary between different actors, having the potential to facilitate the flow of information. This actor is a fundamental platform for disseminating information and increasing participation of different actors. The regional and indigenous REDD+ Groups do not have a strong role yet in the national arena. The strengthening of these regional spaces and their greater integration in communication networks could help improve the flow of communication with local actors.

The results of the study outline a smaller group of principal actors that form the center of interactions concerning REDD+ at a national level. It is shown that only 21 principal actors represent $40 \%$ of the interactions in the information network and $57 \%$ in the collaboration network, constituting a nucleus of leadership at the national level. The group of 21 principal actors is mainly formed of environmental NGOs (national and international) and government actors. Likewise, it is worth highlighting the absence of actors representing economic growth within this group. The MEF and the Ministry of Agriculture and Irrigation (MINAGRI), which determine an important part of public policy concerning economic growth and agricultural expansion, are not among the group of principal actors identified in the study. Their absence could prove to be a barrier to progress towards the REDD+ objective of reducing deforestation, given that they are the ones who determine public policies that influence the drivers of deforestation.

\section{References}

Brockhaus M and Di Gregorio M. 2012. A brief overview: Component 1 on national REDD+ policies and processes. CIFOR Brief 13, CIFOR, Bogor, Indonesia.

Brockhaus M, Di Gregorio M and Carmenta R. 2014. REDD+ policy networks: Exploring actors and power structures in an emerging policy domain. Ecology and Society. Forthcoming.

Che Piu H and Menton M. 2014. Context of REDD+ in Peru:Drivers, actors and institutions. CIFOR Occasional Paper 106. CIFOR: Bogor, Indonesia.

Espinoza $R$ and Feather C. 2011. The reality of REDD+ in Peru: between theory and practice. AIDESEP and FPP: Lima, Peru.

Forest Trends. 2014. REDDX - Tracking forest finance. Accessed 4 November 2014. http://reddx.forest-trends.org

MINAM (Ministry of Environment). 2014. Hoja Informativa: Resultados y avances del Proyecto REDD+ MINAM. MINAM: Lima, Peru.

Perla J, Sotes J, Menton M and Fatorelli L. 2014. Analisis de las redes políticas de REDD+ en el Perú. CIFOR unpublished report.

Scott J. 2000. Social Network Analysis: A Handbook. London: Sage.

Wasserman S and Faust K. 1994. Social Network Analysis: Methods and Applications. Cambridge, United Kingdom: Cambridge University Press.

\section{Acknowledgments}

This study forms part of the policy module of the Global Comparative Study on REDD+ by CIFOR. A part of the methodology is based on the research of the network Comparing Climate Change Policy Networks (www.compon.org). We thank all the interviewed actors for sharing their ideas and time with us. We would also like to thank Maria Brockhaus and Monica DiGregorio for their support during the research, the analysis and the writing process, and the copy editors for their suggestions to improve the text: Rachel Carmenta, Laura Kowler, Jazmín Gonzales and Augusto Castro. We thank the funders of the project: the Norwegian Agency for Development Cooperation (NORAD), the Australian Agency for International Development (AUSAID), the Department for International Development of the United Kingdom (DFID-UK) and the European Commission (EC). 
RESEARCH PROGRAM ON

Forests, Trees and Agroforestry
This research was carried out by CIFOR as part of the CGIAR Research Program on Forests, Trees and Agroforestry (CRP-FTA). This collaborative program aims to enhance the management and use of forests, agroforestry and tree genetic resources across the landscape from forests to farms. CIFOR leads CRP-FTA in partnership with Bioversity International, CATIE, CIRAD, the International Center for Tropical Agriculture and the World Agroforestry Centre.

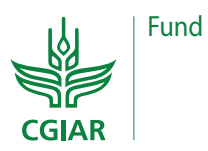

Norad

\section{Australian Aid}

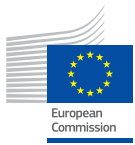

NTL

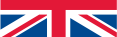

UKaid 